Proceedings of the 2018 International Scientific Conference 'Economic Sciences for Agribusiness and Rural Economy' No 2, Warsaw, 7-8 June 2018, pp. 174-179

\title{
CHANGES IN THE LEVEL OF TECHNICAL AND SCALE EFFICIENCY OF THE FOOD SECTOR ENTERPRISES IN POLAND IN THE YEARS 2006-2016
}

\author{
Sylwester Kozak, $\mathrm{PhD}^{1}$; Karolina Kossowska, $\mathrm{BA}^{2}$
}

Faculty of Economic Sciences, Warsaw University of Life Sciences - SGGW

\begin{abstract}
This article empirically analyses evaluation of efficiency of Polish food producers. Technical and scale efficiency indices are measured using the non-parametric DEA method. The study is based on the annual financial reports of 51 sugar and confectionery producers operating in 2006-2016. The research revealed that technical efficiency of enterprises ranged from 82 to $93 \%$, with the highest levels in periods of considerable increasing macroeconomic conditions in periods of 2006-2007 and 2013-2016. Most of companies characterised with the high efficiency and increasing return to scale. Throughout the entire period companies characterized with high scale efficiency at the interval of $87-93 \%$.
\end{abstract}

Keywords: technical efficiency, DEA method, food sector

JEL codes: O3, O32, L660

\section{INTRODUCTION}

Technical and scale efficiencies are important parameters determining the profitable functioning of the enterprise and the sector in which it operates. Appropriate efficiency allows for proper transformation of the inputs into the outputs of the company's operations. In Poland, the food sector has experienced significant transformations after entering the European Union. The surviving competition from enterprises operating in other EU countries and the need to maintain and expand own market share have become strong motivations for improving the efficiency of operations. These goals were achieved, i.a. due to improvements in technology and methods of management, as well as optimisation of operating costs and search for the economy of scale.

The goal of this article is to assess the level of technical efficiency (the VRS version) and scale efficiency of the food sector enterprises in Poland in 2006-2016. The non-parametric Data Envelopment Analysis (DEA) method was applied for measuring the efficiency of enterprises. The calculations were carried out using the STATA statistical programme (the DEA package). The research covers food sector enterprises of the subsection 'Production of sugar and confectionery products' (No 3113 according to the North American Industry Classification System - NAICS). The sector was chosen due to the relatively large group of presented enterprises, as

${ }^{1}$ Corresponding author: Nowoursynowska 166, 02-787 Warsaw, Poland, Sylwester_kozak@sggw.pl, +4822 5934249

${ }^{2}$ Corresponding author: Nowoursynowska 166,02-787 Warsaw, Poland, k.kossowska@hotmail.com, +48225934249 
well as significant weight and contribution to the production of the entire food sector. The research sample consists of 51 companies with the average value of the annual sales at PLN 350 million and the average value of assets at PLN 353 million. The enterprises have the status of: joint-stock company, limited liability company and co-operative. The annual financial data were downloaded from the EMIS database. According to the authors' knowledge, the research on the efficiency of enterprises operating in this section of the food sector is rather limited. This article fills in the missing gap and makes a significant contribution to efficiency research of the food sector.

The remaining part of the article has the following structure. The next section is a review of literature on the methods of measuring efficiency and their applications in the food sector. The next one presents the economic situation of the sector of production of sugar and confectionery in Poland and the research methodology, and the further presents the results and their discussion. The entire analysis is summarised in the conclusions.

\section{EFFICIENCY OF FOOD ENTERPRISES - LITERATURE REVIEW}

Efficiency is an important and useful measure of business performance. It indicates that with the growth of efficiency the competitiveness of the firm and its ability to preserve the market position increases. Efficiency assessment is considered as a complementary tool for the traditional firm evaluation basing only on financial indicators. Measurement of efficiency allows to synthetically evaluating the business management, including transformation of inputs into the outputs of the firm's operations.

The research by Chen et al. (2015) indicates that the measurement of the firm's effectiveness is crucial for the strategic assessment of individual economic sectors. It allows identifying the best contractors in the industry and their sources of competitive advantage. This measure extends the scope of the firm's evaluation, because focusing solely on financial indicators leads to underestimation of the assessment of the firm's market competitiveness.
The analysis of the technical and scale efficiencies of enterprises is an important part of the research evaluating their performance. Efficiency research has been particularly widespread since the 1980s, and its measurement is carried out using two basic groups of methods: parametric and non-parametric. The parametric group of methods: Thick Frontier Approach (Berger, Humphrey, 1991), Stochastic Frontier Approach (Aigner et al., 1977), Distribution Free Approach (Khoo-Fazari et al., 2013). They are based on estimation of the Cobb-Douglas production function, which defines the relationship between inputs and outputs of the production process. Non-parametric methods do not require any assumptions regarding the functional dependency between inputs and outputs of the firm's operation. The efficiency frontier is determined based on empirical data using linear programming. Non-parametric methods do not take into account the impact of random factors on the efficiency and do not include measuring potential errors. The basic non-parametric method is the Data Envelopment Analysis - DEA (Charnes et al., 1978).

The economic literature contains rather limited group of studies examining the production enterprises' performance with parametric or non-parametric efficiency measures. The most common method of evaluating of enterprises is the assessment using economic and financial indicators. These methods are often considered as fundamental analysis and include such measures as: labour productivity, profitability of assets and equity or the cost-effectiveness of the enterprise (Baran et al., 2016).

The study on the dairy sector in Poland in the period of 1999-2010 tested the technical and scale efficiency (Baran, 2013). Based on evaluation of 750 dairies the research indicates that the dairies operate with increasing scale efficiency and argues that further consolidation of the dairy sector might lead to an increase in effectiveness of the entire sector and improvement of its economic results.

Likewise Wiendlmeier (2001) examining milk processing enterprises in Germany indicates an existence of a favourable impact of the economy of scale on their performance. The study additionally states that the increase in the production scale could enable to achieve a significant reduction in the unit price of 
dairy products. In turn, Rodmanee and Huang testing efficiency of the food industry enterprises in Thailand with the two-stage DEA analysis found that enterprises with low operating profitability show low efficiency as well (Rodmanee and Huang, 2013). In Poland the research conducted with non-parametric DEA method on the meat processing enterprises operating in 2006-2011 indicates that during this period their average efficiency had an upward trend (Jarzębowski, 2014).

\section{SUBJECT AND METHODOLOGY OF RESEARCH}

The performance of the sector of producers of sugar and confectionery products was rather improving during the period of 2006-2016 (Fig. 1). The sales of the sugar and sugar product producers rose from EUR 1.2 billion to 1.4 billion and the sales of the chocolate and sweets producers from EUR 0.5 billion to 0.8 billion. The only one drop in sales occurred in 2009 , which could be considered as a result of the global financial crisis.

For investigating the changes in the efficiency of the producers of sugar and confectionery products the efficiency scores were calculated by the DEA method. The DEA method is a linear programming technique which is used for constructing a frontier that could be used to evaluate the relative efficiency of identical decision making units (DMUs). For this reason the deviation of the DMUs from the idealised production output of the virtual DMU is captured. DEA might take into consideration either Constant Returns to Scale (CRS) applied by Charnes et al. (1978) or Variable Returns to Scale (VRS) elaborated by Banker et al. (1984). The CRS model assumes that enterprise transfers inputs into outputs in the same way irrespective to its scale of operation. Oppositely the VRS model assumes that with the increase of the scale of its operation the enterprise can transfer inputs into outputs more or less efficiently. Based on it we can recognise, respectively, increasing VRS model and the decreasing VRS model. Additionally DEA assumes the efficiency can be improved by reducing the inputs (input-oriented version) or increasing the outputs (output-oriented version).

In the current paper, the output-oriented VRS-DEA approach is employed. The choice is motivated by the fact that, apart from the maximising profits, the one of the most important goals of the food firms is to expand and maintain the market share. In addition, the review of literature indicates that input-oriented DEA should be used for the assessment of enterprises conducting regulated activities, e.g. energy or natural

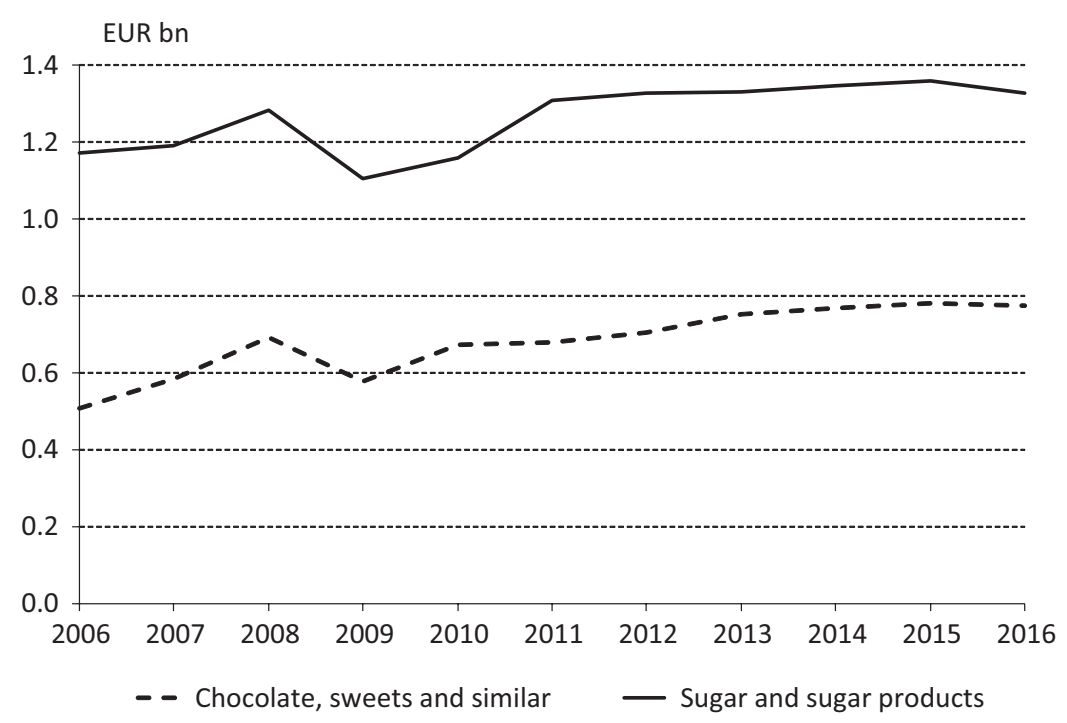

Figure 1. Sales of the producers of sugar and chocolate products in Poland

Source: own calculation based on EMIS data. 
gas suppliers. In such cases, the production price is determined administratively and the efficiency can be improved by minimising inputs. The output-oriented DEA is recommended for evaluation of the majority of market oriented enterprises (Murillo-Zamorano, 2004).

The VRS-DEA efficiency score for the $i$-th food sector enterprise is calculated by solving the following problem (Coelli et al., 2005):

$$
\min _{\theta, \lambda} \theta
$$

$$
\begin{gathered}
\text { Subject to }-y_{i}+Y \lambda \geq 0 \\
\theta x_{i}-X \lambda \geq 0 \\
N 1^{\prime} \lambda=1 \text { and } \lambda \geq 0
\end{gathered}
$$

where:

$y_{i}-$ vector of outputs;

$x_{i}-$ vector of inputs;

$N 1$ - unitary vector with the Nx1 dimension;

$\lambda-$ vector of constants with the Nx1 dimension.

The computed parameter $\theta$ lies between 0 and 1 . The computed efficiency score is equal to 1 if the entity is considered as efficient and otherwise inefficient. $\lambda$ is the assigned weight to an entity.

\section{RESULTS AND DISCUSSION}

The first stage of the data analysis involves calculation of the scale efficiency and the technical efficiency in the version of Variable Return to Scale (VRS). Taking into account the studies of (Chen et al., 2015) and (Rodmanee and Huang, 2013) the following variables were included into calculation of the efficiency scores:

- Input 1: cost of material and products sold (PLN thousand);

- Input 2: cost of operation (PLN thousand);

- Input 3: fixed assets (PLN thousand);

- Output 1: sales (PLN thousand);

- Output 2: gross profit (PLN thousand).

The results indicate that technical efficiency of sugar and confectionery producers were high and relatively stable during the analysed period (Fig. 2). Two significant drops in the technical efficiency appeared in 2008 and 2011-2012, what could be considered, among others, as a probable result of the financial crisis of 2008-2009, the euro public finance crisis of 2011-2012 and the disturbance in the Polish food market affected by the EU sanctions imposed on the Russia Federation.

The analysed sector operates with a high though more variable scale efficiency. Its values falling below 0.9 indicate that there is still ability to take advan-

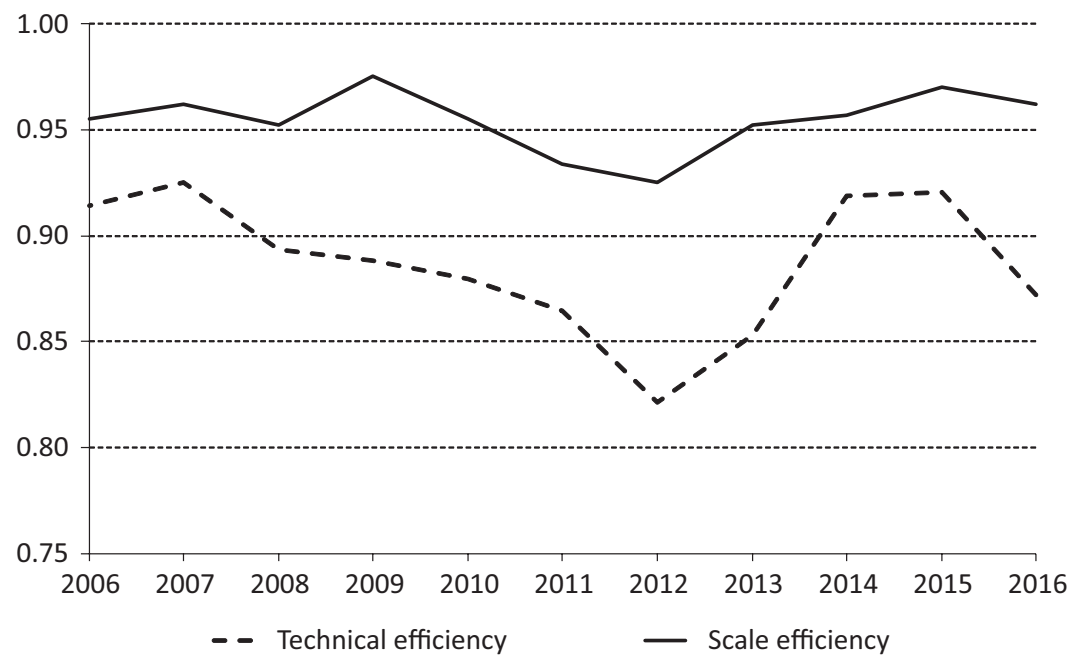

Figure 2. Technical (VRS) and scale efficiencies of the sugar and confectionery producers Source: own calculation based on EMIS data. 


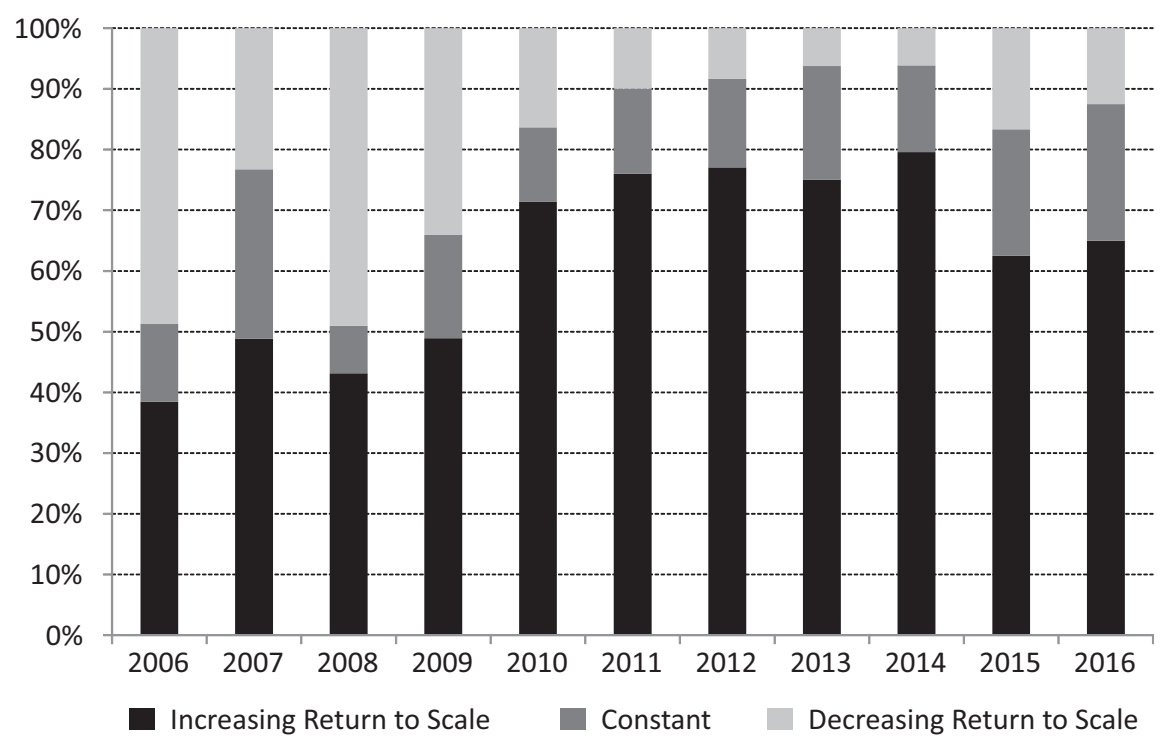

Figure 3. Distribution of types of returns to scale of the sugar and confectionery product producers

Source: own calculation based on EMIS data.

tage of consolidation in the sector and to increase the scale of operation of individual entities. Especially such opportunity appears after the year 2009. In this period most of enterprises operated with the increasing return to scale (Fig. 3).

\section{CONCLUSIONS}

The study on the technical and scale efficiency of sugar and confectionery product producers operating in Poland in 2006-2016 draws to the following conclusions:

- Enterprises operate with high and stable technical efficiency ranging between 82 and $93 \%$ and its value is in some extend impacted by the macroeconomic environment and the performance of the entire food sector;

- The sector shows high, though significantly variable scale efficiency. However enterprises have ability to take advantage form increasing scale of their operations and improve their economic performance. The results indicate that there is still room for further consolidation in the sector.

- Most of enterprises operate in the increasing return to the scale and have possibility to expand their operations and improve their competitiveness.

\section{REFERENCES}

1. Aigner, D., Lovell, C., Schmidt, P. (1977). Formulation and estimation of stochastic frontier production function models. Journal of Econometrics, 6 (1), pp. 21-37.

2. Banker, R., Charnes, A., Cooper, W. (1984). Some Models for Estimating Technical and Scale Inefficiencies in Data Envelopment Analysis. Management Science, 30 (9), pp. 1078-1092.

3. Baran, J. (2013). Efficiency of the production scale of Polish dairy companies based on Data Envelopment Analysis. Acta Scientiarum Polonorum. Oeconomia, 12 (2), pp. 5-13.

4. Baran, J., Wysokinski, J., Staš, D., Samolejova, A., Lenort, R. (2016). Efficiency of Polish metallurgical industry based on Data Envelopment Analysis. Metalurgija, 55 (2), pp. 245-248.

5. Berger, A., Humphrey, D. (1991). The Dominance of Inefficiencies over Scale and Product Mix Economies in Banking. Journal of Monetary Economics, 20, pp. 117-148.

6. Charnes, A., Cooper, W., Rhodes, A., (1978). Measuring the efficiency of decision making units. European Journal of Operational Research, 2 (6), pp. 429-444.

7. Chen, C., Delmas, M., Lieberman, M. (2015). Production frontier methodologies and efficiency as a performance measure in strategic management research. Strategic Management Journal, 36, pp. 19-36. 
Proceedings of the 2018 International Scientific Conference 'Economic Sciences for Agribusiness and Rural Economy' No 2, Warsaw, 7-8 June 2018, pp. 174-179

8. Coelli, T.J. (n.d.). A guide to DEAP version 2.1 (online publication). Retrieved from: http://www.owlnet.rice. edu/ econ380/DEAP.PDF [Accessed 31.05.2018].

9. Coelli, T., Prasada, D., O’Donnell, C., Battese, G. (2005). An Introduction to efficiency and productivity analysis. Springer, New York.

10. Khoo-Fazari, K., Yang, Z., Paradi, J. (2013). A Distribution-Free Approach to Stochastic Efficiency Measurement with Inclusion of Expert Knowledge. Journal of Applied Mathematics, 1-21.
11. Murillo-Zamorano, L. (2004). Economic Efficiency and Frontier Techniques. Journal of Economic Surveys, 18 (1), pp. 33-77.

12. Rodmanee, S., Huang, W. (2013). Efficiency evaluation of food and beverage companies in Thailand: An application of relational two-stage DEA. International Journal of Social Science and Humanity, 3 (3), pp. 202-205. 